\title{
Arteterapia y fibromialgia: lenguajes del cuerpo
}

\author{
Araceli GuIOTE GONZÁLEZ ${ }^{1}$ \\ aguiote@hotmail.com
}

Enviado: 04/04/2011

Aceptado: 12/10/2011

\section{RESUMEN}

El texto pretende ofrecer una parte de un estudio de investigación, realizado a través de la Universidad de Ciencias de la Educación y Bellas Artes de Granada, sobre una intervención en Arte terapia mediante un estudio de caso, de una mujer, afectada por fibromialgia.

Para ello, presentaré en primer lugar, un breve resumen sobre el significado de la fibromialgia. En segundo lugar, expondré el encuadre de los talleres de Arteterapia y en tercer lugar, ilustraré un análisis arteterapéutico del proceso de la intervención del estudio de caso.

En el comentario analítico del proceso creativo de la participante, incluiré referencias contrastadas con la literatura reciente, sobre psicoterapias creativas aplicadas a personas que han sufrido dolencias crónicas a través del cuerpo.

Palabras clave: Fibromialgia, Arte terapia, cuerpos, somatización, psicoterapias creativas.

\section{Referencia normalizada}

Guiote González, A. (2011). "Arteterapia y fibromialgia: lenguajes del cuerpo". En Arteterapia: Papeles de arteterapia y educación artística para la inclusión social Vol.: 6. Páginas 119-133. Madrid. Servicios de publicaciones UCM.

\section{SUMARIO}

Introducción. Estudio de caso. Conclusión. Referencias bibliográficas.

\section{Art-therapy and fibromyalgia: lenguajes of the body}

\begin{abstract}
The text aim to provide a part of a research study, conducted through the University of Science Education and Fine Arts of Granada, on an intervention in art therapy through a case study, of a woman affected by fibromyalgia.

First I will present a brief summary of the meaning of fibromyalgia. Secondly, I will set the frame of art therapy workshops. And thirdly, an analysis will illustrate the process of the art therapist intervention of the case study.

The analytical commentary on the creative process of the participant includes references contrasted with the recent literature on creative psychotherapy applied to people who have suffered chronic ailments through the body.
\end{abstract}

Keywords: Fibromyalgia, Art-Therapy, bodies, somatitation, creative psycotherapy.

\section{CONTENTS}

Introduction. Case of study. Conclusion. References.

\footnotetext{
${ }^{1}$ Facultad de Ciencias de la Educación y Bellas Artes de Granada.
} 


\section{INTRODUCCIÓN}

¿Fibriomialgia?, ¿Qué es la fibromialgia? Es una pregunta difícil de responder. Actualmente, en la literatura sobre la enfermedad de la fibromialgia, profesionales como: Yunus, Masi, Muller, Wolfe, Colegio Americano de Reumatología, Forseth y Gran, Buskila, Gedalia, Prescott, Raspe y Croft (1995), entre otros autores, no se ponen de acuerdo en lo que se refiere a sus causas, orígenes, desencadenantes e incluso, podemos encontrar contradicciones entre los diferentes teóricos.

Existen numerosas teorías al respecto lo que no facilita sentar unas bases objetivas, claras y coherentes sobre la etiología. Dada la dificultad de distinguir la variedad de síntomas que aparecen en la enfermedad sin tener causas directas, tienden a crear gran confusión a los profesionales de diferentes ámbitos, y a los mismos familiares.

¿Cómo podríamos definirla? (Gómez P .2009: 23) expone que "la palabra significa dolor en los músculos y en el tejido fibroso (ligamento y síntomas). Es un síndrome (conjunto de signos y sintomas) que ocasiona dolores generalizados. Es una enfermedad dolorosa, no articular, que involucra a los músculos y es la causa más común del dolor músculo esquelético crónico y generalizado. Castilla A.M (2007:5), afirma que se trata de un síndrome crónico caracterizado por dolor generalizado, que puede llegar a ser invalidante, de etiología desconocida, evolución variable y con frecuencia asociado a otras patologías para las que no existe criterios comunes para el diagnóstico y tratamiento".

El Colegio Americano de Reumatología identifica a la fibromialgia como un "trastorno músculo esquelético con dolor generalizado espontáneo y una sensibilidad exagerada en diferentes puntos como características principales y distintivas. Una persona será identificada con fibromialgia si cumple los criterios que se describen":

- Historial crónico de dolor generalizado: dolor de la parte izquierda del cuerpo, dolor de la parte derecha del cuerpo, dolor en las cervicales, el pecho y zona debajo de la cintura, dolor de hombro y nalga.

- Dolor en al menos 11 de los 18 puntos sensibles. La palpación digital será de aproximadamente $4 \mathrm{~kg}$ de peso y para que el punto se considere "positivo" el sujeto deberá constatar que fue doloroso.

- El dolor generalizado deberá estar presente durante al menos 3 meses. La presencia de un trastorno clínico secundario no excluirá el diagnóstico de fibromialgia.

En el área psicológica, mi propia experiencia me ha derivado a reflexionar sobre las características comunes y diferencias entre las personas que sufren la fibromialgia y las personas que no la sufren. Reflexionar sobre el límite que existe entre unos y otros, y cerciorar, que en ocasiones, ese límite puede ser muy estrecho. 
Tras ahondar en el estudio y análisis de otras investigaciones y fuentes de referencia de los rasgos de la personalidad de los sujetos que tienen fibromialgia, se puede decir que los sujetos que sufren ésta enfermedad presentan unos rasgos y unas características presentes en la población general, tales como: patrones en torno al narcisismo, melancolía, angustia, hipersensibilidad, depresión, irascibilidad, inseguridad interior, necesidad de autoafirmación, grados de agresividad, sentimientos de culpa y de rechazo (Gómez, P. 2009: 215-258), una serie de conductas y/o percepciones, en las cuales cada uno de nosotros a lo largo de nuestra experiencia vital nos podríamos identificar en mayor o menor medida.

Desde una mirada psicoanalítica en relación al significado cultural de la fibromialgia, (Gómez, P: 223-225), argumenta que la angustia y las defensas levantadas contra ésta, constituyen la base de la sintomatología. El análisis, lo hace teniendo en cuenta que el sujeto se construye desde la vinculación social y cultural, y teniendo en cuenta, que las condiciones de vida imperantes en toda cultura engendran ciertos temores que pueden responder a peligros externos (las fuerzas naturales o los enemigos), a las formas que adoptan las relaciones sociales (desencadenamiento de la hostilidad por opresión, injusticia, dependencia forzada) o a tradiciones culturales (sometimiento de la mujer), sin tener en cuenta su origen.

La pulsión de goce inherente en la actualidad en la cultura del placer inmediato propicia vías para evitar el afrontamiento de la angustia. Gómez, P (2007:234) nombra las siguientes vías:

La racionalización, negación, narcotización y la evitación (evitar toda idea, sentimiento capaz de despertarla).

Luego una persona podrá estar más o menos condicionada a ciertos temores, en términos generales, pues afectan a todos los individuos. Pero, en cambio, los sujetos que padecen fibromialgia no solo comparten los temores comunes en todos los individuos de una cultura sino que además sufren otras angustias que se distinguen por una intensidad mayor.

La diferencia principal entre estar bajo los síntomas de la fibromiálgia y no estarlo, estriba en que presentan "menos recursos y destrezas interpersonales para poder afrontar los malestares inherentes en nuestro sistema sociocultural" Cuevas, A (2010) y esto les supone un desgaste mayor de los mecanismos de defensas, siendo expuestos a mayor grado de dolor y sufrimiento. Dicho estado se prolonga de manera constante en el tiempo, desarrollando un estado de enfermedad.

\section{ESTUDIO DE CASO}

He hecho uso del estudio de caso como estrategia de muestreo, junto con otras estrategias como: observación participante, notas de campo, análisis del discurso, imágenes y objetos resultantes, escritura y toda producción creativa como memoria de la evolución de los talleres, para llevar a cabo una metodología cualitativa orientada en una investigación basada en las artes, investigación-acción. 


\section{Hipótesis de trabajo:}

¿Puede el Arteterapia ser una terapia efectiva, para tomar conciencia de algunas de las características psicopatológicas asociadas a esta enfermedad y posibilitar alivio y mejora en la autogestión del dolor?

\section{ENCUADRE}

Centro: Asociación de Fibromialgia de Granada (AGRAFIM).

Duración de los talleres: 2 meses y medio. Dos veces por semana; hora y media cada taller.

\section{Objetivos:}

Tras analizar el colectivo y ahondar en las principales problemáticas presentadas, entre ellas las dificultades manifestadas para poder escuchar al cuerpo de una manera diferente a las voces del dolor y la distancia tan grande entre sus cuerpos, los portadores de la enfermedad y sus emociones, establecí unos objetivos generales:

- Orientar la práctica del arte para organizar aspectos de la propia subjetividad.

- Construir otras vías de comunicación con uno mismo y los otros, alternativas a la palabra.

- Ligar el trabajo de la creatividad con la función de "reparación", entendiendo la obra como una "re-creación" (Klein, 1999).

Y unos objetivos específicos como:

- Posibilitar la reestructuración interiorizada de la imagen corporal dolorida.

- Proporcionar herramientas óptimas a través de la expresión creativa, para una efectiva autogestión del dolor.

- Aliviar el dolor mediante una mayor toma de conciencia de su estado corporal y emocional.

- Utilización de los talleres como medios para canalizar las emociones bloqueadas y de malestar en la subjetividad de las participantes.

- Escuchar al cuerpo de una manera diferente al dolor. 


\section{Talleres de arteterapia:}

Los talleres se estructuraban en tres partes: una primera parte dedicada para comentar aspectos de la sesión anterior; una segunda, para el proceso de creación y una última parte, el turno de palabra donde se verbaliza el proceso de creación.

A la hora de organizar el material recogido durante las sesiones de arteterapia, he tenido en cuenta el trabajo de Shaverian J. (1991) en su investigación sobre la clasificación de tipos, funciones y valor de las imágenes. He dividido la exposición de la evolución de los talleres, en tres fases.

Nuestra participante es una mujer de unos 45 años, a quién recientemente le han diagnosticado la enfermedad. Tiene conjuntamente otra enfermedad en los huesos.

Pese a ello, es una mujer con muchas ganas de vivir, ilusionada por aprender y sobre todo, ilusionada con la expresión artística, actividad practicada por ella en el pasado y olvidada, tras los avatares de la vida que la fueron sumergiendo en episodios dramáticamente dolorosos.

\section{PRIMERA FASE: SESIONES 1-5. "IMÁGES SIGNOS"}

La primera fase del taller la he denominado "Imágenes Signos" Shaverian J. (1991). Como la autora expone, es frecuente en una primera parte de los talleres, que las imágenes creadas no presenten una fuerte carga emocional; tienden a no coincidir el discurso de la participante acerca de lo creado con la imagen; tienen una función de establecer vínculos; ocupar un lugar dentro del taller; servirán como preámbulo para la creación de otras imágenes con mayor carga emocional.

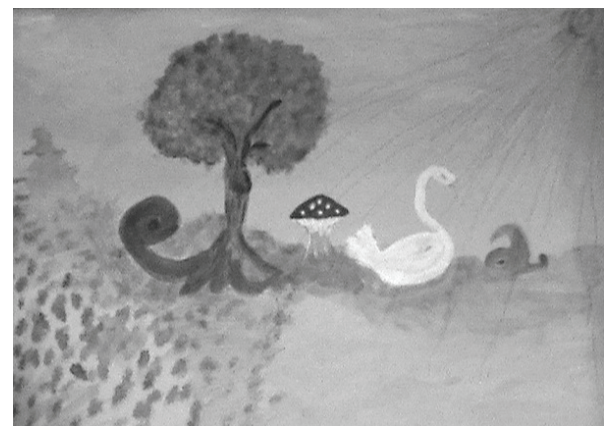

Fig. 1

El primer taller empezó con la propuesta: "trabajar con la inicial del nombre".

Ella habla de su obra como la representación de su amor hacia la naturaleza, hacia los árboles, las raíces, mediante un discurso idealizado sobre el ser humano en la integración con el todo. Cree en la vida como un lugar idílico y mágico.

Si observamos la imagen, podemos contrastar que los símbolos, los colores y las formas están lejos de representar un entorno idílico o en equilibrio. 
La estética es vaporosa, velada, con una cierta confusión. La inicial "E" está arraigada a la raíz de un árbol, que no se sabe bien si está hundiéndose o flotando; el nombre se está moviendo en el vaivén del agua. Cada uno de los elementos son confusos. Y sumergiéndonos en éstas veladuras nos encontramos a un sol en la esquina, cuyos rayos, atraviesan gran parte de la composición, de manera diagonal, el cual, transmite una sensación de crispación, o como si estuviesen arañando al soporte y a los elementos de los mismos por los que atraviesa, estando lejos de representar lo que su discurso describe como un sol que proporciona amor a la tierra.

Tras comentar el discurso recogido por ella y contrastarlo con la imagen, podemos recoger una distancia entre el discurso verbal sobre el sentido mágicoespiritual del ser humano y el mundo y la imagen creada, que expresa sensaciones internas opuestas, por parte de la participante, en éstas primeras tomas de contacto en los talleres.

En la siguiente obra, titulada "VIDA", responde a la propuesta "hacer una presentación de ti misma a través de los materiales".

Su discurso gira en torno al Reiki, a la energía cósmica que nos conecta a todos con la madre tierra y de las manos se desprenden dicha energía que está siendo transmitida a las montañas. Las manos mandan energía para que nazca y florezca vida.

Llama la atención la manera de representar la energía. Nuevamente, hay una gran distancia entre el discurso y la imagen. La energía, que podría ser como el sol en la composición anterior, está siendo desintegrada, en un momento de eclosión, de explosión donde parece chispear en grandes bloques de fuerza que golpean a las montañas más allá de estar infundando energía o calor. A través de la imagen se percibe una composición desbordante.

\section{SEGUNDA FASE: SESIONES 6-10. "EL ÁRBOL DEL AMOR"}

Nos adentramos en una fase intermedia del proceso creativo, donde la participante se conecta con la tensión que genera el enfrentare a sus dificultades y desde la relación transferencial con el material, elaborará conflictos. A través de la observación de la creación de las imágenes, podrá verbalizar conflictos inconscientes.

Ésta obra titulada "EL ÁRBOL DEL AMOR" responde a la propuesta de la lectura de una poesía Mi segundo nombre se llama Soledad (Coria, C: La Vanguardia 2010). En éste taller, es de especial interés el proceso de creación. Trabaja agitadamente, nerviosa, con rapidez de ejecución, parece querer traspasar la obra y conforme pasa el tiempo, éste modo de hacer se acentuará durante el proceso. 


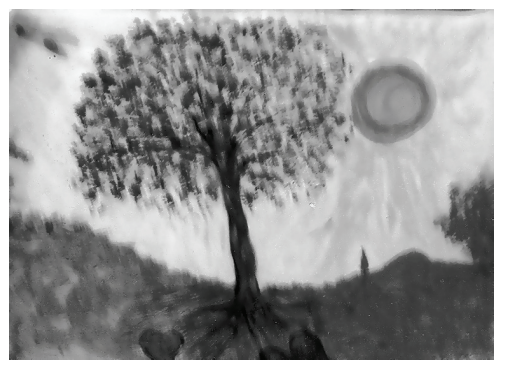

Fig. 2

Pude apreciar unos símbolos que se repiten como: sol, árbol, raíces, y observar cómo están cambiando estéticamente y la manera de ser representados. Estéticamente la composición está más definida, con mayor orden, claridad y figuración. El sol está contenido por un límite grueso y rojo y los rayos no arañan la obra de manera tan agresiva como podíamos apreciar en obras anteriores. El árbol arraigado a la tierra, parece rozar a los corazones que están sepultados. Los cambios también se pueden denotar en los colores, ahora son cálidos, intensos y armónicos.

En el turno de palabra la participante tras la lectura de la poesía, subrayará frases de la misma, que ella personalmente comparte con la autora del escrito. Las frases serán las siguientes:

\section{Los hombres reclaman a sus parejas como madres y las tratan como niñas...}

Tenemos que querernos primero a nosotras mismas para que nos quieran. (Coria, C: La Vanguardia 2010).

Asocia estas frases con relaciones sexuales negativas en una relación sentimental anterior.

Ahora podemos recoger una ampliación en el discurso, hay dos discursos, mientras se mantiene el mecanismo de defensa de la idealización en torno al amor a la naturaleza, la participante, tras observar la obra, narrará experiencias sexuales desagradables y angustiosas. En una experiencia en concreto dirá: "Tenía miedo a ser abandonada si no cumplía los deseos del otro, tenía miedo a que se fuera con otra mujer sino hacia lo que él quería".

Pasa de un discurso a otro como si fuesen bloques de piedra diferentes sin tener ninguna relación el uno con el otro. Su concepción del mundo ideal parece ser una burbuja que no se rompe, aún, tras recordar su pasado traumático.

En éste taller, se llevará la imagen a su casa y continuará trabajando con ella. Escribió la siguiente poesía: 


\begin{abstract}
Sol del alma
en un mundo nuevo

entre sonido de palabras

cediendo espacios, evitando negociar

nuestro segundo nombre es SOLEDAD

igual que dice Elena Coria
\end{abstract}

Esta poesía me permitió hacer algunas asociaciones en relación a la repetición de los símbolos y el discurso en torno a los mismos, asociaciones como: sol podría hacer referencia a ella; el árbol referenciar el estado de sus emociones en relación a la enfermedad; el corazón, el origen, emociones anteriores a la enfermedad, el Self en relación a la creación. En la obra los coloca bajo la tierra, en las raíces de su estado emocional.

Cuando habla del árbol, dirá que ese árbol en verdad no existe, que es inventado, que ha oído hablar de la posibilidad de árboles con esas características y que cree que podría existir. Espera que esos corazones den fruto, vida al árbol y que se expandan al exterior.

Mencionar que a nivel transferencial podía recoger dificultades para mirar algo en concreto mientras rodeaba con las palabras la lectura de la poesía creada; una sensación de evitación, se hacía presente en el espacio del taller.

En la siguiente imagen, realizada desde una propuesta libre, pintó el sol en medio de la composición y unas manos que contenían a un corazón saliéndo de la tierra.

Pude observar que ahora el árbol ha desaparecido, hay una relación directa entre el sol y el corazón. El sol contenido en un límite rojo intenso, donde apreciaba nuevamente una estética chispeante, desintegrada.

Citará: "Cuando miro la obra, la emoción es tan grande que no le puedo poner palabra. Algo se me escapa".

En el turno de palabra expresa su agradecimiento a la vida, siente que los talleres le están acogiendo y permitiéndole retomar actividades que le sientan bien en relación a la creación.

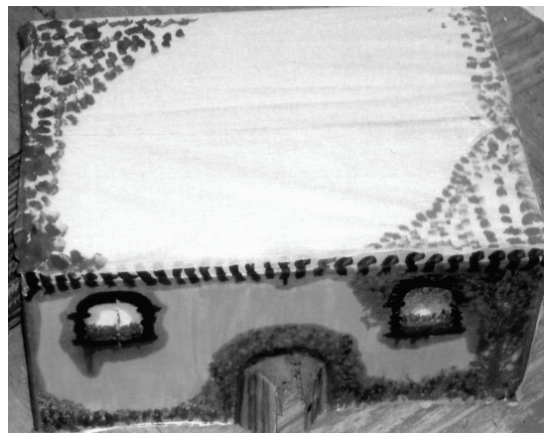

Fig. 3 
Estas imágenes, tomando en cuenta la clasificación de imágenes de Shaverian J (1991), se denominan, imágenes contenedoras de emociones, encarnan emociones que abren una vía directa con el inconsciente, aunque a la participante, en el momento de realizarlas se le escapa de su comprensión, tendrán que ser retomadas más adelante para poder acceder al entendimiento de la totalidad de los conflictos que está trabajando.

"LA CASA DE MIS SUEÑOS". En éste taller se trabajó con la propuesta de "transformar una caja, trabajando su interior y su exterior".

La estética de la caja transformada en una casa, responde a una estética de cuento, colores intensos, llenos de detalles que evocan un hogar cercano a la naturaleza.

En el turno de palabra, asociará la casa con: pájaros, refugio, agua, lugar de seguridad, tranquilidad, paz. A través de la observación de la obra, desplegará un segundo discurso donde narra las dificultades y conflictos de su realidad en torno a diversos ámbitos como: el laboral, salud física, emocional, lugar de residencia y amistades.

Especialmente se detendrá en su casa, la real, no la de la imagen. Dice sentir odio hacia ella, porque vive en un espacio muy reducido, en un bloque lleno de vecinos y ruidos, en una parte muy transitada de la ciudad.

Se manifiesta LA DUALIDAD acerca de la representación de sus deseos en la obra, con las dificultades para gestionar una realidad que le angustia.

Se le olvida una parte de la propuesta mencionada, "trabajar el interior de la caja". Tras recordárselo, hará dos ausencias en los siguientes talleres. Cuando retoma el taller, es especialmente significativo el cambio que se produce en la selección de los materiales y el modo de usarlos. Normalmente su técnica preferida era el óleo, acuarela, pincel; técnicas líquidas que le facilitaba fluir y dar rienda suelta a sus emociones. Ahora, siente dolor en las manos y por ello, escoge papel forrado, con el cual, corta y pega. Es una técnica muy rápida, relajante y evitativa. El proceso de creación terminará muy pronto, apenas presta atención y desea dar por terminada la obra sin detenerse demasiado a comentarla. Este taller es una excepción en relación a la dinámica y modos de crear anteriores.

Me llamó mucho la atención que en la obra, no hay elementos decorativos. Observándo el interior de la caja, la parte externa de la caja tiene que estar completamente invertida. Trabaja desde un inicio el exterior de la caja, de tal manera que después le dificultaría trabajar el interior. Me parece esta obra muy ilustrativa en relación a una de las características principales de la enfermedad, que explica (Panhofer. H 2005), acerca de la distancia abismal entre los dolores físicos y los dolores emocionales. Podemos ver proyectada en la obra que dentro de una misma propuesta, la creación ha acabado siendo dos obras invertidas. El interior, vacío pero llamativo, seductor y el exterior, decorado, detallista, policromático, proyectando una estética ideal de la naturaleza. Las personas que sufren la fibromialgia, pese al dolor o el malestar, un rasgos común en ellas/os es que suelen presentar muy buen estado físico y preocupación por la estética (Cuevas. A. 2007). En la Asociación Agrafim, (Martín L, 2009) psicólogo clínico, podía recoger en los 
resultados de un test (elaborado para analizar los rasgos de la personalidad de las personas afectadas por la fibromialgia), una muestra de 107 personas, una respuesta común a la pregunta sobre cómo se viven o sienten internamente. Ellas/os la/lo definían como "sentimiento de vacío crónico". Me parecía ilustrador éste dato recogido por mi compañero de trabajo con la obra de creación, en la cual, de manera simbólica, se estaba trabajando aspectos internos. Es un dato, aún no objetivo por que el estudio de Leandro M.A, no ha terminado de concluir, pero me permitió asociar informaciones y las transmito en éste texto desde una posición reflexiva y no propiamente como dato empírico.

También me llamó la atención que por primera vez en los talleres se ausentó dos veces y cuando volvió presentaba dolor en las manos. Éste hecho me llevó a reflexionar en torno al uso intencionado del cuerpo físico, de la enfermedad, como mecanismo de defensa para evitar trabajar aspectos de su subjetividad en el desarrollo de los talleres. Probablemente mi propuesta se habría planteado de manera anticipada. Quizás todavía no presentaba recursos para afrontar una propuesta tan simbólica como trabajar el interior de una caja y observamos el levantamiento de los mecanismos de defensa. En la tesis doctoral de Panhofer. H (2005: 205-212), una de sus conclusiones gira en torno a las resistencias y el beneficio de la enfermedad, lo define como "la alianza de la enfermedad". Hartas de sentir que luchan, el dolor físico se convierte en el "amigo más fiel". Nunca les falla, en los momentos difíciles, desarrollan inconscientemente una forma de reaccionar apoyándose en ese "amigo fiel", no distinguiendo entre el "no puedo" y "no quiero". De ésta manera, a través de la enfermedad se construye un muro con el cual protegerse a la conexión o enfrentamiento de emociones. Así mismo, revisando otras fuentes de investigación, encontré un dato curioso procedente del doctor Feldman. M (2008) quién no podía entender por qué los pacientes que él citaba, cancelaban su turno al llegar a la puerta de su consultorio en la clínica de la Duke University. Feldam, médico psiquiatra, tardó un tiempo en darse cuenta de que la razón era que junto a su nombre, en la puerta de su consultorio decía "Medicina Psicosomática" y la gente estaba convencida de que se les iba a decir "todo se debe a un problema psicológico", para muchos sinónimos de locura.

El cuerpo es dolor y no entienden que tenga alguna relación con sus cogniciones, sus experiencias vividas y emocionales ligadas a ésta, su personalidad, su "yo".

A partir de éste taller reelaboré unos objetivos prioritarios: como ayudar a diferenciar su discurso plástico del discurso verbal. Señalar que quizás está representando su deseo y que a veces las cosas no son como deseamos; intentar enlazar su discurso con lo plástico y transmitir el mensaje de que en los talleres se trabaja hasta donde se pueda y que ella puede parar su trabajo en el momento que lo desee (con una intención de evitar la ausencia como un mecanismo de evitación). 


\section{TERCERA FASE: SESIONES 10-13. "LA CAÍDA"}

La tercera fase del taller se estableció en función de una imagen que rompe tanto estéticamente como en contenido con las obras anteriores.

Esta obra encarna las emociones que ha estado trayendo de manera fragmentada en obras anteriores. En relación al discurso en el turno de palabra, no hay alternancia de dos discurso

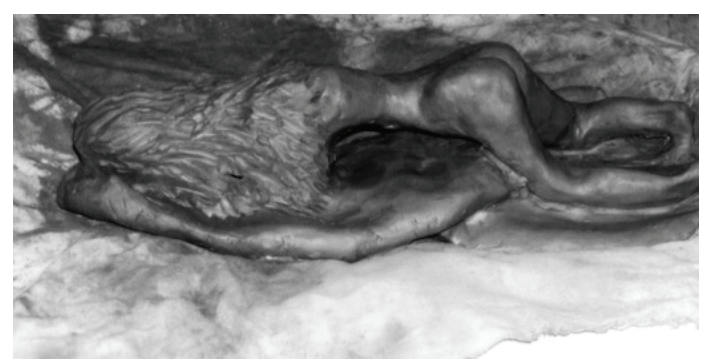

Fig. 4 "La caida" (idealización y angustia) sino que sólo hay uno: LA CAIDA, en la representación de la condición humana desde la soledad absoluta frente a sus emociones. Es de interés la manera en cómo expresa dichas emociones, lo hace desde una posición de resignación, como algo normalizado que me hacía asociar con la posición frente a la enfermedad. Algo muy significativo será cuando explica que para poder crear esta imagen estuvo pensando detenidamente como era su cuerpo, como era: sus pies, su piel, musculatura, tobillos, caderas...en ese pensar cómo es su cuerpo creó el cuerpo de la imagen.

Estéticamente el cuerpo es un escorzo, donde las emociones de dolor y sufrimientos están magistralmente logradas al ser expresadas a través del cuerpo y no en el rostro, el cuerpo canaliza la emoción en bruto, es la emoción de la angustia.

En la obra "RENACER" realizó un trabajo de reparación tras la simbolización anterior.Trabaja desde la obra anterior. Logra cambiar su significado tras modificar, la posición de los pies, las manos y la cabeza. Supone un punto de inflexión en el proceso del Arte terapia. Se puede recordar a (Paín, S. Agosto 2001), el concepto de "transformación" que desarrolla la autora, en el cual, lo define como el proceso donde la participante "transfiere" a la materia carga emocional para trabajar elementos traumáticos, mediante la creación.

Observamos como la participante trae lo repetitivo de sus conflictos emocionales, pero la relación o vínculo con la materia y el acto de crear, le permite introducir un tercer elemento, que posibilita el cambio de lugar subjetivo. Hay algo nuevo en la repetición. 
Estéticamente el escorzo expresa crispación tras modificar la cabeza, pero los pies y las manos se están preparando para la acción, para levantarse.

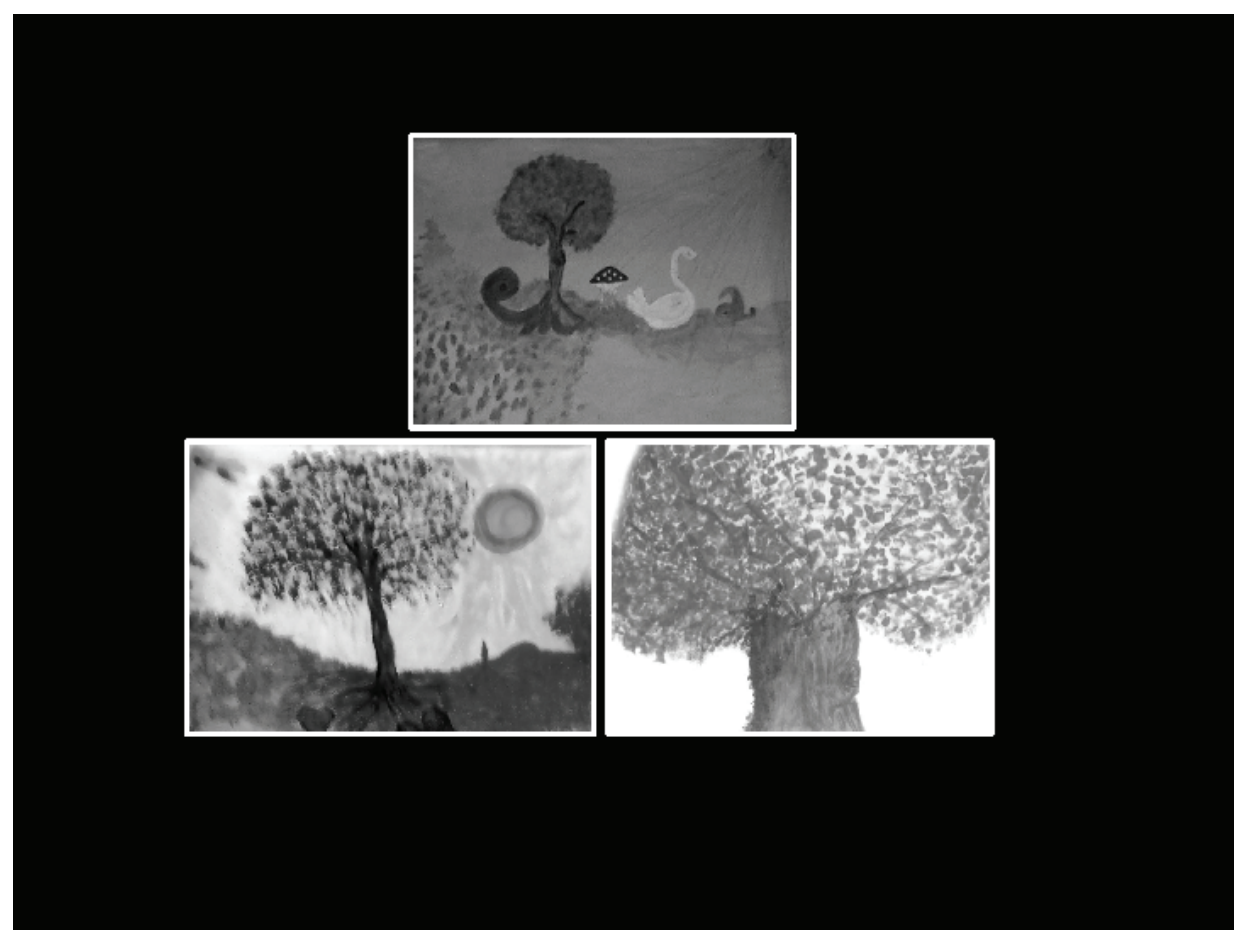

Fig. 5

El árbol es un símbolo que se ha ido repitiendo a lo largo de los talleres, observándo la evolución del mismo, podemos apreciar que hay un cambio en la repetición tanto estéticamente como de significado. En el turno de palabra hablará sobre el deseo de querer representar un árbol que no existe y que cree que nunca va a encontrar. Cuando lo observa, a ella misma le llama la atención que el árbol está divido drásticamente en dos colores, en dos zonas, primero lo titula "equilibrio y melancolía" finalmente, tras observarlo más detenidamente le cambia el nombre: "La fuerza".

\section{CONCLUSIONES}

A la pregunta planteada en la hipótesis de trabajo ¿Puede el Arteterapia ser una terapia efectiva, para tomar conciencia de algunas de las características psicopatológicas asociadas a esta enfermedad y posibilitar alivio y mejora en la autogestión del dolor?

Primera respuesta: 
-Si, puede ser una terapia efectiva para la toma de conciencia de algunas características psicopatológicas asociadas a la enfermedad porque:

Ha modificado la posición subjetiva inicial a otra, con una ampliación de la misma, accediendo a una mayor conciencia de su subjetividad.

Se han producido cambios en el discurso. En la primera fase del taller, estaba caracterizado por una idealización de la vida. En una segunda fase del taller, alternaba el primer discurso mencionado con otro, marcado por la angustia. Y en la tercera fase, ya no hay dos discursos, sino uno, en el cual, toma plena conciencia de su sufrimiento.

La obra "La Caída", encarna emociones que ha estado trayendo de manera fragmentada en obras anteriores y posibilita que la participante lo observe de manera unificada.

Ésta obra le permite simbolizar, observar, tomar conciencia y pensar sobre su sufrimiento. A través de la creación, puede mirar y sostener una imagen que representa una de las características principales de la fibromialgia, el dolor. Toma conciencia que para ella, la fibromialgia supone una acumulación de alteraciones emocionales que la han posicionado en estados de dolor extremo y continuado en el tiempo.

A partir de ese momento, llevó a cabo, uno de los objetivos generales establecidos, de ligar la materia a un trabajo de "reparación", haciendo uso del objeto creado ("Obra "la caída") para hacer una re-elaboración de la materia (Obra "la fuerza"). Por consiguiente, dicho trabajo, le permite pensar y elaborar conflictos inconscientes desde la expresión artística.

Ha desarrollado un proceso dinámico, en movimiento, modificando la posición inicial hacia otras posibilidades de mirar la obra y narrar su historia.

Segunda respuesta: si, puede el Arteterapia ser efectiva para posibilitar alivio y mejora en la autogestión del dolor, porque:

Ha reforzado aspectos de su identidad vinculadas al acto de crear. Tras el trabajo de la creación y turno de palabra, ella, describe experimentar sensaciones de satisfacción, bienestar y cita "conectarse con una parte de ella misma anterior a la enfermedad".

Dice retomar aspectos de su vida que había abandonado. Se siente satisfecha al volver a practicar la actividad artística. Solía practicarla en el pasado y citará: "los talleres me contienen", ha experimentado un cambio de actitud en sus relaciones sociales y familiares. "Me estaba cerrando a mi misma porque me sentía irritada constantemente, ahora, estoy volviendo a salir con mis amigos, retomando cosas que estaba abandonando"

Los talleres le han permitido canalizar la angustia en relación al reconocimiento social de su enfermedad y transferir en las obras la carga emocional inicial transformándola en imágenes que le devolvía un reflejo amable y satisfactorio de sí misma 
Por último concluir, que dado el desconocimiento aún sobre la etiología, causas, desencadenantes y síntomas, considero que puede ser favorecedor para los profesionales que trabajan con personas que sufren fibromialgia, el hacer reuniones periódicas y regulares, para el intercambio de información, diálogo, reflexión sobre la evolución de la práctica profesional. Dicho espacio puede ser efectivo para una mejor comprensión de la fibromialgia y por tanto, aumentar la efectividad en la orientación y aplicación de la práctica profesional. 


\section{REFERENCIAS BIBLIOGRÁFICAS}

CASTILLA, A. (2007). "La Fibromialgia y sus implicaciones personales y sociales en los pacientes de la comunidad de Madrid”. Ed Paidos. Madrid.

CUEVAS. A. (2009) Personalidad, dolor y estrategias de afrontamiento en pacientes con fibromialgia. Pag 32-37

DENNERKER K. (2010) "Body and Expresión: Art Therapy with Rheumatoid patients". American Journal of Art Therapy. Mayo 91, Vol, 19. Fascículo Pág. 15 EBSCO Industrias, Inc.

GÓMEZ. P (2007) Fibromialgia cómo vencerla desde el cuerpo y la mente Barcelona. Editorial Integral.

HAWARD, (1990) R. HOWARD, Art Therapy as an isomorphic intervention in the treatment of a client with posttraumatic stress disorder, Art Therapy. Journal of the American Art Therapy Association 28 , Pág. 79-86.

KIRMAYER, L. J. y ROBBINS, J.M (1991) Current concepts of somatization: research and clinical perspectives, Washintong DC, American Psychiatric Press Inc.

PAIN, S, Entrevista. Gabriel Pisano. Ignota (2001). "Identidad y devenir subjetivo". Psicoanálisis: Cambios y permanencias. Julio/Agosto Pág. 161-179.

PANHOFER, H. (2005). El cuerpo en psicoterapia. Barcelona. Editorial Gedisa.

SHAVERIAN, J (1991). The Reveling Image: analitical art psycotherapy in theory and practice, London, Jessica Kingsley Publishers.

ON LINE:

SAVNEET TALWARS: Accesing traumatic memory throught art making. An Art therapy trauma protocol. Creative Community Arts Studio. United States. 19 October 2006.

http://web.ebscohost.com/ehost/detail?vid=12\&hid=11\&sid=1521b595-e026-4838-92fd-5e157e9d83cf\%40sessionmgr14 